Article

\title{
Control of Aflatoxin Production of Aspergillus flavus and Aspergillus parasiticus Using RNA Silencing Technology by Targeting aflD (nor-1) Gene
}

\author{
Ahmed M. Abdel-Hadi ${ }^{1}$, Daniel P. Caley ${ }^{2}$, David R. F. Carter ${ }^{2}$ and Naresh Magan ${ }^{1, *}$ \\ 1 Applied Mycology Group, Cranfield Health, Vincent Building, Cranfield University, Bedford \\ MK43 0AL, UK; E-Mail: ahmed_alhadi2000@yahoo.com \\ 2 Current address - School of Life Sciences, Oxford Brookes University, Oxford, OX3 0BP, UK; \\ E-Mail: d.cayley@brookes.ac.uk (D.P.C.); d.carter@brookes.ac.uk (D.R.F.C.) \\ * Author to whom correspondence should be addressed; E-Mail: n.magan@cranfield.ac.uk; \\ Tel.: +44-1234-758083; Fax: +44-1234-658083.
}

Received: 18 April 2011; in revised form: 8 June 2011 / Accepted: 15 June 2011 /

Published: 17 June 2011

Abstract: Aspergillus flavus and Aspergillus parasiticus are important pathogens of cotton, corn, peanuts and other oil-seed crops, producing toxins both in the field and during storage. We have designed three siRNA sequences (Nor-Ia, Nor-Ib, Nor-Ic) to target the mRNA sequence of the aflD gene to examine the potential for using RNA silencing technology to control aflatoxin production. Thus, the effect of siRNAs targeting of two key genes in the aflatoxin biosynthetic pathway, aflD (structural) and aflR (regulatory gene) and on aflatoxin $B_{1}\left(A F B_{1}\right)$, and aflatoxin $G_{1}\left(A F G_{1}\right)$ production was examined. The study showed that Nor-Ib gave a significant decrease in aflD mRNA, aflR mRNA abundance, and $\mathrm{AFB}_{1}$ production (98, 97 and 97\% when compared to the controls) in A. flavus NRRL3357, respectively. Reduction in aflD and aflR mRNA abundance and $\mathrm{AFB}_{1}$ production increased with concentration of siRNA tested. There was a significant inhibition in aflD and $\mathrm{AFB}_{1}$ production by $A$. flavus EGP9 and $\mathrm{AFG}_{1}$ production by A. parasiticus NRRL 13005 . However, there was no significant decrease in $\mathrm{AFG}_{1}$ production by $A$. parasiticus SSWT 2999. Changes in $\mathrm{AFB}_{1}$ production in relation to mRNA levels of aflD showed a good correlation $(R=0.88 ; P=0.00001)$; changes in aflR mRNA level in relation to mRNA level of $a f l D$ also showed good correlation $(R=0.82 ; P=0.0001)$. The correlations between changes in aflR and aflD gene expression suggests a strong relationship between these 
structural and regulatory genes, and that aflD could be used as a target gene to develop efficient means for aflatoxin control using RNA silencing technology.

Keywords: siRNA; aflD (nor-1) gene; aflR gene; aflatoxin; real-time PCR

\section{Introduction}

Aflatoxins are secondary metabolites produced by Aspergillus flavus and A. parasiticus that occur in nuts and cereal crops. These compounds have a high acute toxicity, as well as immunosuppressive, mutagenic, teratogenic, and carcinogenic activities and are classified as group 1 carcinogens by the International Agency for Research on Cancer [1].

Controlling aflatoxin production is of critical importance. Mainly traditional control methods including cultural practices such as pesticides and the development of resistant cultivars, pest resistance have been used. However, these have not always been successful in maize and in groundnuts. There is thus interest in exploring alternative means to control or reduce aflatoxin production.

RNA interference technology (RNAi) has received much attention in biology. The reason for this enthusiasm is that RNAi can rapidly ablate specific messenger RNA (mRNA) species by inducing their degradation via cellular protein machinery collectively named the RNA-induced silencing complex [2]. Short-interfering double-stranded RNA (siRNA) is synthesized and introduced through common transfection methods into cells, where they serve to guide the RNA degradation machinery to the select target gene. RNAi is an effective tool to investigate gene function, and may also be a useful tool to quench the expression of undesirable gene products.

RNA silencing in filamentous fungi has been carried out using plasmid constructs expressing a hairpin dsRNA structure controlled by an inducible or constitutive promoter [3-6]. Liu et al. [7] demonstrated silencing of the cryptococcal CAP59 and ADE2 genes by double-stranded RNA homologous to these genes in the basidiomycetous yeast Cryptococcus neoformans.

Application of siRNA-mediated RNAi has also been reported in cultured cells from fungi. Katri and Rajam [8] reported that ornithine decarboxylase (ODC) was specifically silenced by treating germinating spores with synthetic $23 \mathrm{nt}$ siRNA in Aspergillus nidulans. Doubled-strand of RNA (dsRNA) was also delivered directly into protoplasts of Phytophthora infestans, which belongs to the fungus-like Oomycetes [9].

In A. flavus and A. parasiticus the expression of the aflD (nor-1), a gene encoding an enzyme that catalyzes the conversion of the first stable aflatoxin biosynthesis intermediate, norsolorinic acid, to averantin $[10,11]$ is a key structural gene in the biosynthetic pathway. Furthermore, aflR is a pathway regulatory gene coding for proteins shown to be involved in transcriptional activation of most of the structural genes [12]. Recent studies have shown that there may be a relationship between the ratio of $a f l R$ and $a f l S$ (the associated regulatory gene) genes which is influenced by environmental factors [13]. Recently, studies by Abdel-Hadi et al. [14,15] showed the potential use of aflD transcription as a good marker to discriminate between aflatoxigenic and non-aflatoxigenic strains contaminating peanuts while aflR failed to differentiate between these strains. They showed that the expression patterns of $a f l D$ were related to changing water activity in stored peanuts. In peanuts, aflR was found not to 
change in the same consistent way with water availability in peanuts. Thus, the expression pattern of this structural gene was selected as a target gene for silencing.

The objective of this study was to determine the potential of siRNA for silencing the target gene (aflD) and phenotypic aflatoxin control in strains of A. flavus and A. parasiticus.

\section{Materials and Methods}

\subsection{Fungal Strain and Growth Conditions}

In this study, four aflatoxigenic strains (Aspergillus flavus NRRL3357, Aspergillus flavus EGP9, Aspergillus parasiticus NRRL 13005 and Aspergillus parasiticus SSWT 2999) have been used. The strains were sub-cultured on Malt Extract Agar (20 g malt extract, $2 \mathrm{~g}$ peptone, $15 \mathrm{~g}$ agar per liter) for 7 days at $25^{\circ} \mathrm{C}$ in the dark.

\subsection{Preparation of Protoplast}

Protoplasts were prepared from actively growing mycelium; a spore suspension of the strains sub-cultured in $200 \mathrm{~mL}$ of Yeast Extract Sucrose (YES) broth $(20 \mathrm{~g}$ yeast extract, $150 \mathrm{~g}$ sucrose per liter), then incubated for $24 \mathrm{~h}$ on a shaker at $200 \mathrm{rpm}$ in the dark at $25^{\circ} \mathrm{C}$. The mycelium was harvested by filtration through Miracloth. One gram of mycelia was transferred into $20 \mathrm{~mL}$ of filter sterilized enzyme solution (per $20 \mathrm{~mL}: 17 \mathrm{~mL}$ of $\mathrm{H}_{2} \mathrm{O}, 2 \mathrm{~mL}$ of $0.2 \mathrm{M} \mathrm{NaPO}_{4}\left(\mathrm{pH} 5.8\right.$ ), $0.4 \mathrm{~mL}$ of $1.0 \mathrm{M} \mathrm{CaCl}_{2}$, $1.4 \mathrm{~g}$ of $\mathrm{NaCl}, 0.2 \mathrm{~mL}$ of $\beta$-glucuronidase (105 U/mL; Sigma), $200 \mathrm{mg}$ of lysing enzyme (Sigma), and $50 \mathrm{mg}$ of driselase (Sigma). Mycelia were incubated at $30{ }^{\circ} \mathrm{C}$ with shaking $(80 \mathrm{rpm})$ for $3 \mathrm{~h}$. Protoplasts were separated from intact mycelia by passage through Miracloth into a sterile $50 \mathrm{~mL}$ tube, and $20 \mathrm{~mL}$ of sterile STC buffer (1.2 M sorbitol, $10 \mathrm{mM} \mathrm{CaCl}_{2}, 10 \mathrm{mM}$ Tris- $\mathrm{HCl}$ (pH 7.5)) was added. Protoplasts were pelleted by low-speed centrifugation $(1000 \mathrm{rpm})$ at room temperature for $5 \mathrm{~min}$. The supernatant was carefully removed, and the protoplasts were washed once more in $20 \mathrm{~mL}$ of STC and pelleted by centrifugation as described previously. The protoplast pellet was resuspended in $1.0 \mathrm{~mL}$ of STC buffer, and the protoplasts were counted on a haemocytometer and diluted to $1 \times 10^{5} / \mathrm{mL}$ [16].

siRNA design: Three siRNA sequences were designed by Ambion (Applied Biosystem) to target the mRNA sequence of the aflD gene of A. flavus (accession number EF565463) and purchased from the same company. These siRNA were named as Nor-Ia, Nor-Ib and Nor-Ic (Table 1). Annealing of RNA oligonucleotides and purification by HPLC were performed by the company. An siRNA (control-siRNA) with no sequence homology to any A flavus genome sequence database was also purchased from Ambion.

Table 1. Details of siRNA sequences used in this study.

\begin{tabular}{ll}
\hline siRNA Name & siRNA Sequence \\
\hline Nor-Ia & Sense strand: CAUGUAUGCUCCCGUCCUAUU \\
& Antisense strand : UAGGACGGGAGCAUACAUGUU \\
Nor-Ib & Sense strand: GCAACAGGCCAAGUUUGUCUU \\
& Antisense strand : GACAAACUUGGCCUGUUGCUU \\
Nor-Ic & Sense strand: CAGGCCAAGUUUGUCUUGAUU \\
& Antisense strand : UCAAGACAAACUUGGCCUGUU \\
\hline
\end{tabular}




\subsection{Delivery of siRNA to Protoplast}

All siRNAs were resuspended in water free of RNases at a final concentration of $25 \mathrm{nM}$ and tested on A. flavus NRRL3357. In a sterile $1.5 \mathrm{~mL}$ micro centrifuge tubes, $10 \mu \mathrm{L}$ of each siRNA was mixed with an equal volume of Lipofectin reagent (Invitrogen Life Technologies, UK) and allowed to stand for $15 \mathrm{~min}$ at $20{ }^{\circ} \mathrm{C} .20 \mu \mathrm{L}$ of protoplasts $\left(1 \times 10^{3}\right)$ were added and mixed gently. The tubes were incubated at $20{ }^{\circ} \mathrm{C}$ for $24 \mathrm{~h}$ to allow transfection to proceed [9]. Then the mixture was inoculated in $10 \mathrm{~mL}$ of YES medium with $1.2 \mathrm{M}$ of sorbitol for 5 days at $25{ }^{\circ} \mathrm{C}$ in the dark. Different dilutions of Nor-Ib $(5,10,15,20,25 \mathrm{nM})$ were tested on A. flavus NRRL3357. Twenty five nM of Nor-Ib was tested on Aspergillus flavus EGP9, Aspergillus parasiticus NRRL 13005 and Aspergillus parasiticus SSWT 2999. All experiments were carried out using three biological replicates.

\subsection{Aflatoxin Extraction and HPLC Analysis}

Five $\mathrm{mL}$ of filtrate was extracted with chloroform, and then the extract was evaporated. The residue was derivatized using TFA (Triflouroacetic acid) as described by the AOAC [17]. Sample extracts were analyzed using an Agilent 1200 series HPLC (Agilent, Berkshire, UK) using a 470 fluorescence detector (FLD, G1321A, Agilent) $\left(\lambda_{\mathrm{exc}} 360 \mathrm{~nm} ; \lambda_{\mathrm{em}} 440 \mathrm{~nm}\right)$ and a $\mathrm{C}_{18}$ column (Phenomenex Luna ODS2 $150 \times 4.6 \mathrm{~mm}, 5 \mu \mathrm{m}$; Maccesfield, UK). The analysis was performed using a mobile phase of methanol: water: acetonitrile (30:60:10) at a flow rate of $1 \mathrm{~mL} / \mathrm{min}$ and a run time of $25 \mathrm{~min}$.

\subsection{Isolation of RNA from the Samples and RT-PCR}

Total RNA was extracted from mycelium using the RNeasy and Plant Mini Kit (Qiagen GmbH, Hilden, Germany). A $0.5-1.0 \mathrm{~g}$ sub-sample of the mycelia was ground in a mortar with a pestle in liquid nitrogen. Approximately $250 \mathrm{mg}$ of the mycelial powder was then used for isolation of total RNA. RNA extraction from the ground mycelia was accomplished with the RNeasy and Plant Mini Kit (Qiagen GmbH, Hilden, Germany) according to the instructions provided by the manufacturer. Then RNA was treated with DNase I (RNase free DNase I, Amplification Grade, Sigma) to digest residual DNA in the samples.

TaqMan probes and primer design: Real Time RT-PCR was used to amplify the aflD gene (target gene) and $a f l R$ gene (regulatory gene). The two primers and an internal fluorescence labelled probe used in the reaction were nortaq-1 5'-GTCCAAGCAACAGGCCAAGT-3'; nortaq-2 5'-TCG TGCATGTTGGTGATGGT-3'; norprobe 6FAM TGTCTTGATCGCGCCCG- BHQ2 [18]; AflRtaq-1 5'-TCGTCCTTATCGTTCTCAAGG-3'; AflRtaq-2 5'-ACTGTTGCTACAGCTGCCACT-3', AflRprobe 6FAM AGCAGGCACCCAGTGTACCTCAAC-BHQ2. To create a standard curve, a larger PCR fragment of the aflD (nor-1) gene was generated with the primer nor1 and nor2 [19] (Figure 1a). Different dilutions were prepared from a stock solution by a factor of 10 and the aliquots of the dilutions were used in standard reactions during each setup of the real-time PCR reaction. The concentration of this standard PCR product was determined in a spectrophotometer (WPA light wave Cambridge, UK) and the number of copies was calculated. The concentration of unknown samples was calculated by the CFX96 system (Bio Rad, Hercules, CA) according to the generated standard curve. To create a standard curve for aflR, a larger PCR fragment of the $a f l R$ gene was used. To create the 
standard curve, a larger PCR fragment of the aflR with the following primers AflR1, 5'-CGAGTTGTGCCAGTTCAAAA-3'; AflR2， 5'-AATCCTCGCCCACCATACTA-3' was used (Figure 1b).

Real-time PCR conditions: Amplification was performed using a total reaction volume of $25 \mu \mathrm{L}$ in a MicroAmp optical 96-well reaction plate (Applied Biosystems). For each reaction $12.5 \mu \mathrm{L}$ of TaqMan Universal Master Mix (Applied Biosystems), $2.5 \mu \mathrm{L}$ cDNA, $3 \mu \mathrm{L}$ of primer and probe mix (0.5 $\mathrm{nM}$ primer and $0.2 \mathrm{nM}$ probe), and $7 \mu \mathrm{L}$ of free RNases water. Real Time reactions were performed using the Bio Rad CFX96 platform (Bio Rad, Hercules, CA) with the following conditions: an initial step at $95{ }^{\circ} \mathrm{C}$ for $10 \mathrm{~min}$, and all 40 cycles at $95^{\circ} \mathrm{C}$ for $15 \mathrm{~s}, 55^{\circ} \mathrm{C}$ for $20 \mathrm{~s}$ and $72{ }^{\circ} \mathrm{C}$ for $30 \mathrm{~s}$.

Statistical analysis: All experiments were carried out with 3-4 replicates and repeated twice with similar results. Statistical tests were performed using Statistica version 8 (StatSoft, Inc, 1984-2007) for one-way ANOVA and LSD Fisher was determined at the 95\% confidence limits.

Figure 1. Standard curves from real-time PCR by plotting the threshold cycle $(\mathrm{Ct}) v s . \log _{10}$ initial copy numbers of $a f l D$ gene (a) and $a f l R$ gene (b) amplified with the primer of labeled with FAM. Where E: The efficiency of PCR, $\mathrm{R}^{2}$ value: correlation coefficient.

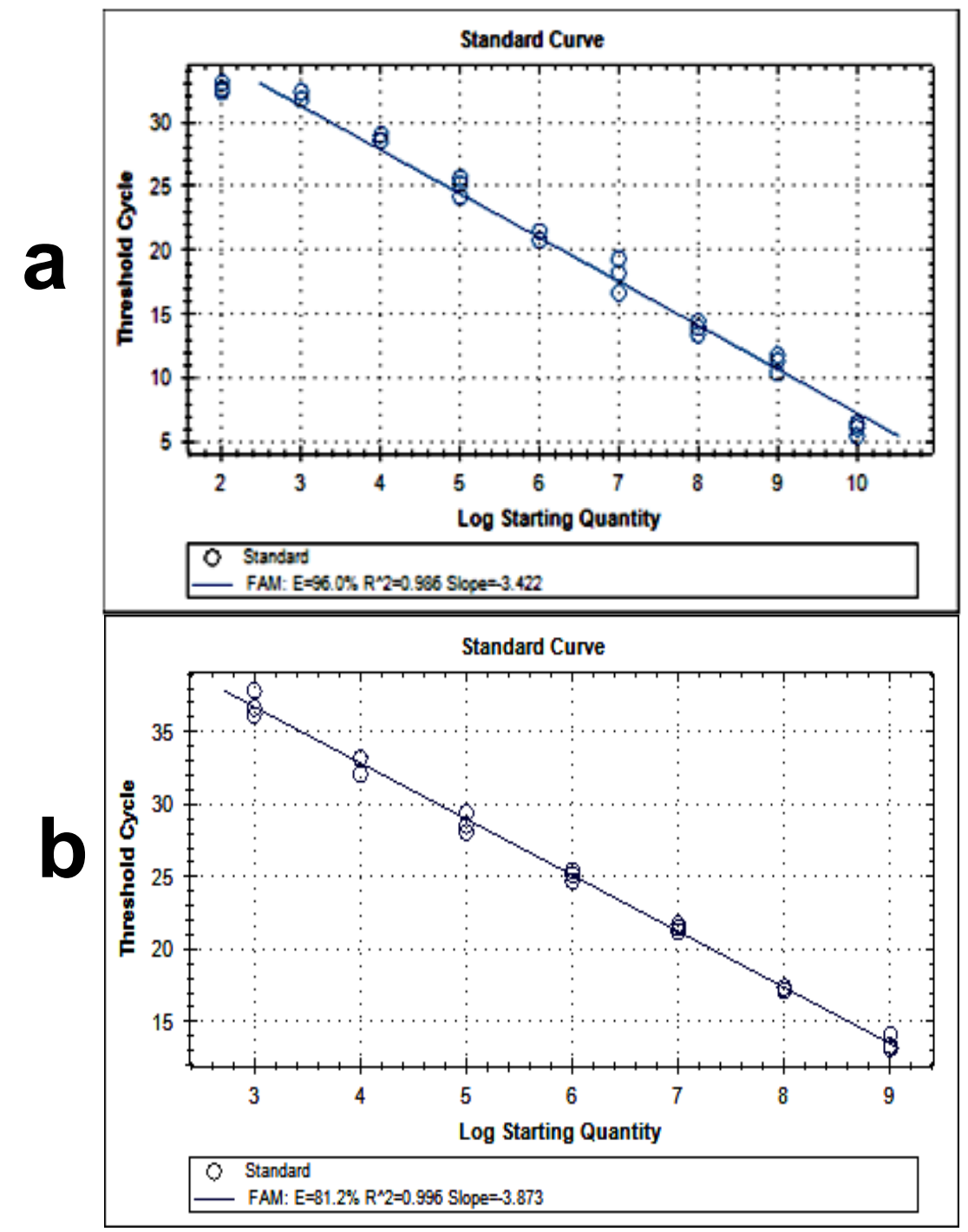




\section{Results}

\subsection{Treatment of Aspergillus flavus NRRL with siRNA}

Quantification of the aflD based on the absolute quantification of copy number by using the calibration curve provided accurate, sensitive and highly reproducible data [20]. Figure 2 shows the changes in aflD and aflR mRNA expression and $\mathrm{AFB}_{1}$ production by A. flavus NRRL3357 after treatment with control-siRNA or three siRNAs (Nor-Ia, Nor-Ib, Nor-Ic) specific to the aflD target gene. Treatment with the control-siRNA had no significant effect on $\mathrm{AFB}_{1}$ production or aflD/aflR mRNA copy numbers. There was a significant decrease $(95,98$, and $91 \%$ of the control level) in aflD mRNA abundance after treating with Nor-Ia, Nor-Ib and Nor-Ic siRNAs respectively, as assessed by real-time PCR. The lack of any effect using the control-siRNA and the knockdown seen with all three aflD siRNAs suggested that the results were not caused by transfection conditions or due to off-target effects.

Figure 2. Effect of siRNA for silencing aflD target gene on aflatoxin $\mathrm{B}_{1}$ production, gene expression of $a f l D$ and $a f l R$ by using real-time PCR of Aspergillus flavus NRRL. Vertical bar indicates standard error, control (untreated with siRNA), and N. Control (treated with unrelated siRNA as a negative control).
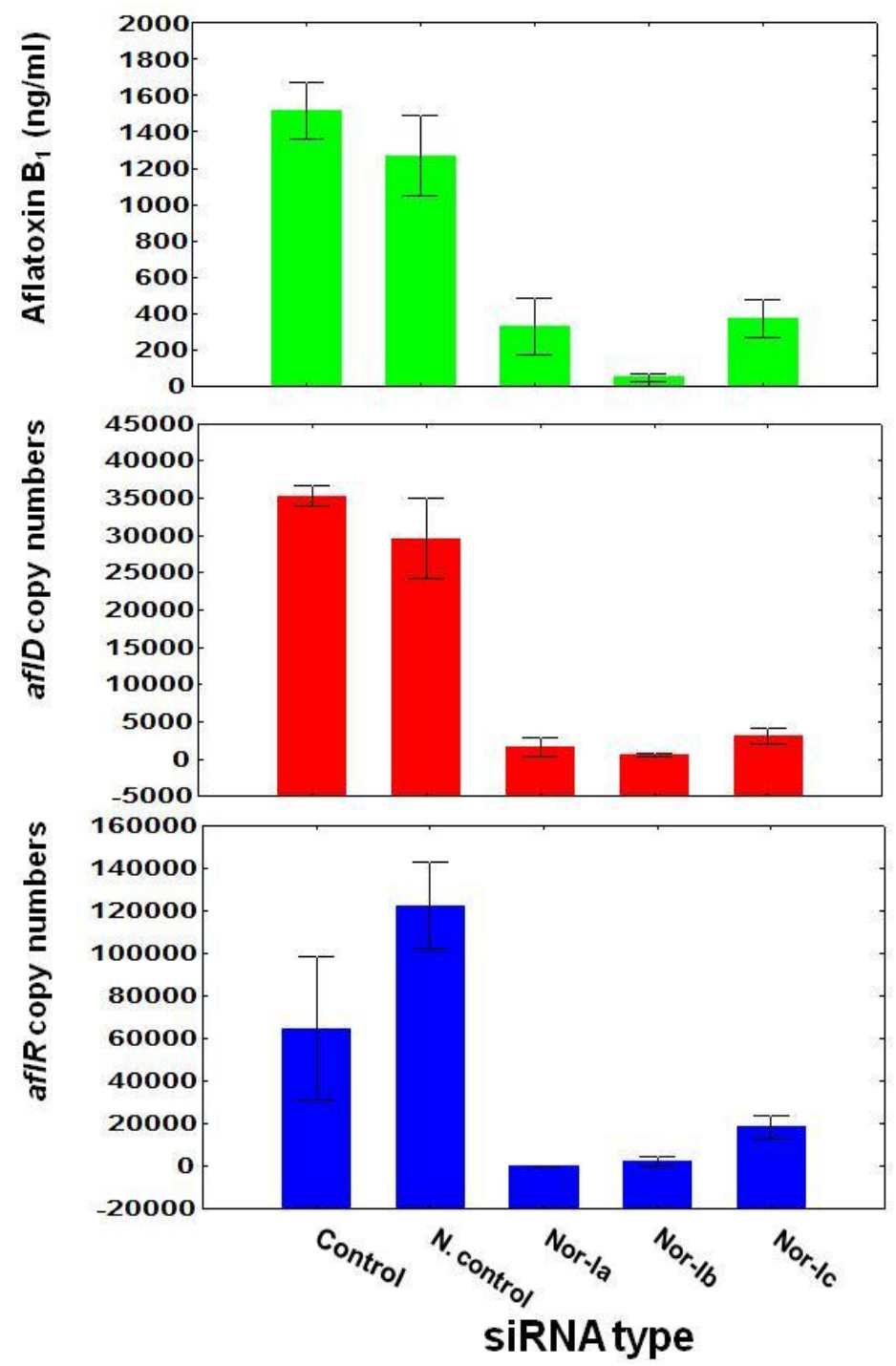
Interestingly, a decrease (99\% (Nor-Ia treatment), 97\% (nor-Ib treatment), and 72\% (Nor-Ic treatment) of the control level in aflR mRNA abundance was also observed following knockdown of aflD. Subsequently, a decrease of $\mathrm{AFB}_{1}$ production as a result of a decrease of aflD and aflR gene expression ((79\% (Nor-1a treated), 97\% (Nor-Ib treated), and 76\% (Nor-Ic treated)) of the control level was obtained. Statistical analysis of the effect of siRNA treatment on aflD gene expression, aflR gene expression and $\mathrm{AFB}_{1}$ production were highly significant (Table $2 \mathrm{a}$ ). There was a good correlation between siRNA effects on aflD and aflR expression $(R=0.82, P=0.0001)$; aflD and $\mathrm{AFB}_{1}(R=0.88$, $P=0.00001)$; and aflR correlated significantly with $\mathrm{AFB}_{1}(R=0.66, P=0.0074)$ (Table 3$)$.

Table 2. (a) Analysis of Variance of the effect of siRNA silencing of the aflD target gene on $\mathrm{AFB}_{1}$ production, expression of aflD gene and aflR gene, and (b) effect of different concentrations of siRNA (Nor-Ib) on $\log \mathrm{AFB}_{1}$ production, log quantification of aflD gene and aflR gene. Key: DF: Degrees of freedom, MS: mean square; P: Probability, F: F value.

\begin{tabular}{lllll}
\hline & DF & MS & F & P \\
\hline (a) & & & & \\
Factor & & & & \\
aflD copy numbers & 4 & $8.58 \times 10^{8}$ & 42.47 & 0.000003 \\
AFB $_{1}$ & 4 & $1.24 \times 10^{8}$ & 18.74 & 0.0001 \\
aflR copy numbers & 4 & $8.16 \times 10^{9}$ & 8.63 & 0.0027 \\
\hline (b) & & & & \\
Factor & & & 10.95 & 0.0003 \\
$\log$ aflD & 5 & 1.87 & 199.13 & 0.00000 \\
$\log$ AFB & & 0.41 & 6.05 & 0.005 \\
$\log$ aflR & 5 & 2.4659 & & \\
\hline
\end{tabular}

Table 3. Statistical correlations between aflD gene, aflR gene and $\mathrm{AFB}_{1}$ production of A. flavus NRRL3357 treated with siRNA (Nor-Ib). Key: R: correlation coefficient, P: Probability, F: F value.

\begin{tabular}{llll}
\hline Correlations & R Value & F & P \\
\hline aflD andaflR & 0.82 & 28.41 & 0.0001 \\
aflD and $\mathrm{AFB}_{1}$ & 0.88 & 47.26 & 0.00001 \\
aflR and $\mathrm{AFB}_{1}$ & 0.66 & 10.039 & 0.0074 \\
$\log$ aflD and siRNA conc. & 0.86 & 46.31 & 0.000 \\
$\log \mathrm{AFB}_{1}$ and siRNA conc. & 0.91 & 77.75 & 0.000 \\
$\log$ aflR and siRNA conc. & 0.45 & 4.07 & 0.06 \\
\hline
\end{tabular}

\subsection{Effect of siRNA Concentrations on A. flavus NRRL3357}

Figure 3 compares the effect of different concentrations of siRNA (Nor-Ib) on quantification of aflD and aflR genes, and $\mathrm{AFB}_{1}$ production by A. flavus NRRL3357. Overall, the best reduction in aflD and aflR mRNA abundance and $\mathrm{AFB}_{1}$ production was at $25 \mathrm{nM}$ siRNA of the concentrations tested. Statistical analysis of the effect of different concentrations of siRNA treatment on aflD, aflR gene expressions and $\mathrm{AFB}_{1}$ production was statistically significant (Table $2 \mathrm{~b}$ ). There was a good correlation in reduction as a result of siRNA treatment between $\log$ aflD and siRNA concentration $(R=0.86$, 
$P=0.000), \log \mathrm{AFB}_{1}$ and siRNA concentration $(R=0.91, P=0.000)$ and low correlation between $\log$ aflR and siRNA concentrations $(R=0.45, P=0.06)$ (Table 3$)$.

Figure 3. Effect of different concentrations of siRNA (Nor-Ib) on Aflatoxin $\mathrm{B}_{1}$ production, gene expression of $a f l D$ and aflR by using real-time PCR of Aspergillus flavus NRRL3357. Vertical bar indicate standard errors of the mean.

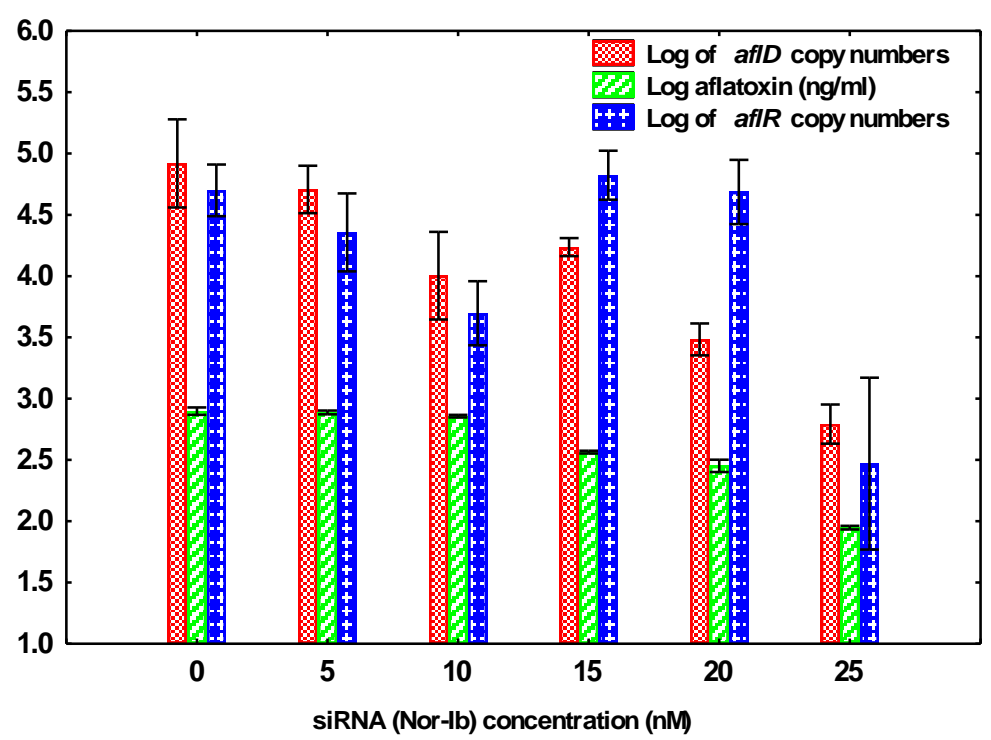

\subsection{Treatment of A. flavus and A. parasiticus with siRNA}

Tables 4, 5 show the effect of treating three aflatoxigenic strains with the chosen concentration of the siRNA ( $25 \mathrm{nM}$, Nor-Ib). There was a significant effect on aflD (target gene), and a concomitant decrease in aflR mRNA abundance and $\mathrm{AFB}_{1}$ production by A. flavus EGP9 treated with siRNA when compared to the control $(99.7 \%, 83.4 \%$, and 89\%, respectively). Treating Aspergillus parasiticus NRRL 13005 with siRNA revealed a reduction in aflD (target gene) mRNA abundance and AFG $_{1}$ production which was statistically significant $(89.4 \%$ and $77.2 \%$, respectively). The data obtained with Aspergillus parasiticus SSWT 2999 after treatment with siRNA showed that there was only a significant effect in aflD mRNA abundance (92.3\%).

Table 4. Aflatoxin $\mathrm{B}_{1}\left(\mathrm{AFB}_{1}\right)$, Aflatoxin $\mathrm{G}_{1}\left(\mathrm{AFG}_{1}\right)$, aflD and aflR expression assayed by control (untreated) and Nor-1b siRNA (treated) on three aflatoxigenic strains. Each value is mean \pm standard error based on three replicates.

\begin{tabular}{|c|c|c|c|c|c|c|c|c|}
\hline \multirow{2}{*}{ Strains } & \multicolumn{2}{|c|}{$\operatorname{AFB}_{1}(\mu / \mathbf{m L})$} & \multicolumn{2}{|c|}{$\mathrm{AFG}_{\mathbf{1}}(\boldsymbol{\mu} / \mathbf{m L})$} & \multicolumn{2}{|c|}{ AflD Copy Numbers $\times 10^{3}$} & \multicolumn{2}{|c|}{ AflR Copy Numbers $\times 10^{3}$} \\
\hline & Un-Treated & Treated & Un-Treated & Treated & Un-Treated & Treated & Un-Treated & Treated \\
\hline A. flavus EPG9 & $0.7 \pm 0.05$ & $0.088 \pm 0.003$ & 0 & 0 & $195.6 \pm 56.9$ & $0.69 \pm 0.2$ & $41 \pm 10.7$ & $6.8 \pm 0.8$ \\
\hline $\begin{array}{l}\text { A. parasiticus- } \\
\text { NRRL13005 }\end{array}$ & $0.15 \pm 0.04$ & $0.05 \pm 0.01$ & $2.7 \pm 0.5$ & $\begin{array}{l}0.6 \pm \\
0.2 \\
\end{array}$ & $22.9 \pm 4.7$ & $2.4 \pm 1.4$ & $0.6 \pm 0.2$ & $0.05 \pm 0.007$ \\
\hline $\begin{array}{l}\text { A. parasiticus- } \\
\text { SSWT2999 }\end{array}$ & $1.48 \pm 0.37$ & $1.1 \pm 0.4$ & $7.8 \pm 1.9$ & $\begin{array}{l}5.5 \pm \\
3.0\end{array}$ & $499.9 \pm 85$ & $43.6 \pm 5.5$ & $0.4 \pm 0.1$ & $0.06 \pm 0.02$ \\
\hline
\end{tabular}


Table 5. (a) Analysis of Variance of the effect of siRNA (Nor-Ib) for silencing aflD target gene on aflatoxin $\mathrm{B}_{1}$, aflatoxin $\mathrm{G}_{1}$ expression of $a f l D$ and aflR genes of three aflatoxigenic strains (a) A. flavus EPG9; (b) A. parasiticusNRRL13005; and (c) A. parasiticus SSWT2999. Key: DF: Degrees of freedom, MS: mean square, P: Probability, F: F value.

\begin{tabular}{|c|c|c|c|c|}
\hline & DF & MS & $\mathbf{F}$ & $\mathbf{P}$ \\
\hline \multicolumn{5}{|l|}{ (a) } \\
\hline \multicolumn{5}{|l|}{ A. flavus EPG9 Factor } \\
\hline aflD copy numbers & 1 & $5.7 \times 10^{10}$ & 11.71 & $0.026 *$ \\
\hline $\mathrm{AFB}_{1}$ & 1 & $7.4 \times 10^{5}$ & 163.06 & $0.0002 *$ \\
\hline \multicolumn{5}{|l|}{ (b) } \\
\hline \multicolumn{5}{|c|}{ A. parasiticus NRRL13005 Factor } \\
\hline aflD copy numbers & 1 & $6.3 \times 10^{8}$ & 17.07 & $0.01 *$ \\
\hline AFG1 & 1 & $6.9 \times 10^{6}$ & 12.34 & $0.02 *$ \\
\hline \multicolumn{5}{|l|}{ (c) } \\
\hline \multicolumn{5}{|c|}{ A. parasiticus SSWT2999 Factor } \\
\hline aflD copy numbers & 1 & $3.1 \times 10^{11}$ & 28.68 & $0.005^{*}$ \\
\hline AFG1 & 1 & $8.3 \times 10^{6}$ & 0.42 & 0.54 \\
\hline
\end{tabular}

* Significant $<0.05 \%$.

\section{Discussion}

This is the first study to use RNA interference to silence one of the important structural genes in the aflatoxin biosynthesis pathway (aflD gene) in both A. flavus and A. parasiticus and to elucidate the function of this gene in aflatoxin production by direct delivery. Previously, it was reported that using direct delivery of dsRNAs or siRNAs could result in sequence specific suppression of this particular gene [21,22]. The application of direct delivery of synthetic siRNA, have been rarely attempted in fungi [23]. RNA interference was discovered after the injection of dsRNA into the nematode Caenorhabditis elegans lead to specific silencing of genes highly homologous in sequence to the delivered dsRNA [21]. Zamore et al. [22] reported that using the Drosophila in vitro system, dsRNA triggers the specific degradation of homologous RNAs only within the region of identity with dsRNA.

Our results showed that all three siRNAs designed to target aflD gene gave excellent levels of silencing. The transient gene silencing was observed at an early stage after 5 days of protoplast regeneration and hyphal growth, with no changes in fungal growth observed between siRNA treated and untreated samples. This suggests that protoplasts have the ability to take up siRNAs from the medium during growth. Recently, Khatri and Rajam [8] reported that germinated spores are capable of taking up siRNAs from the growth medium in the early stages of germ tube extension.

The decrease in mRNA expression of aflD level caused a subsequent decrease in $\mathrm{AFB}_{1}$ production. Changes in $\mathrm{AFB}_{1}$ production in relation to mRNA level of $A f l D$ showed a good correlation $(r=0.88$, $P=0.00001)$. This strongly suggest that aflD is absolutely essential for $\mathrm{AFB}_{1}$ biosynthesis and silencing of aflD gene expression by siRNA may result in accumulation of intermediate compounds and lead to blocking of $\mathrm{AFB}_{1}$ biosynthesis. In general, the aflatoxin gene cluster in A. parasiticus and A. flavus consists of 25 genes spanning approximately $70 \mathrm{~kb}$ [24,25]. Aflatoxin production could be disrupted if any step in the aflatoxin biosynthetic pathway is completely blocked by a specific 
inhibitor. Using siRNA to target aflD (nor-1) gene expression that represents the early enzymatic steps in the aflatoxin biosynthetic pathway could be an appropriate target for inhibiting aflatoxin biosynthesis. Disruption or deletion of the $a f l D$ (nor-1) gene leads to the accumulation of norsolorinic acid and blocks the synthesis of all aflatoxins and their intermediates beyond norsolorinic acid [26]. Previously, it was reported that transformation of A. flavus and A. parasiticus with inverted repeat transgenes (IRT) containing sequence of aflatoxin-specific regulatory gene aflR suppressed aflatoxin production in both pathogenic fungi [27]. Also an aflR-specific IRT was successfully used to suppress the sterigmatocystin (ST) pathway in A. nidulans [28].

It was interesting to note that a decrease in aflR expression was observed following knockdown of aflD and changing in AflR mRNA levels in relation to mRNA level of aflD showed a good correlation ( $R=0.82, P=0.0001)$. One explanation for this reduction in aflR expression could be that there is a similarity in siRNA and the sequence of any of the global secondary metabolite regulatory machinery genes that regulate aflR like LaeA. Another explanation could be that accumulation of intermediate compounds resulting from aflD knockdown may have an indirect effect in suppression of $a f l R$ expression or any of the global secondary metabolite regulatory machinery genes. Butchko et al. [29] described a screen for detecting mutants defective in the sterigmatocystin (ST) gene cluster activity of A. nidulans by use of a genetic block early in the ST biosynthetic pathway that results in the accumulation of the first stable intermediate, norsolorinic acid. They found that three of the mutants were unable to express aflR, which encodes an ST zinc cluster ( $\mathrm{Zn}(\mathrm{II})_{2} \mathrm{Cys}_{6}$ ) transcription factor regulating ST biosynthetic gene expression. The biosynthetic and regulatory genes required for ST production in A. nidulans are homologous to those required for aflatoxin production in A. flavus and A. parasiticus $[30,31]$.

The control siRNA did not lead to knockdown of aflD or aflR, suggesting that the results observed with aflD-specific siRNAs are not the result of a transfection artifact or an off-target effect. Our results support those obtained by Khatri and Ranjam [8]. They suggested that siRNA can cause specific silencing effects, in the polyamine biosynthetic pathway without any off-target effects. However, Jackson et al. [32] demonstrated that siRNAs may cross-react with targets of limited sequence similarity.

To confirm the effect of siRNA silencing, we treated three aflatoxigenic strains with siRNA. There was a significant decrease in aflD (targeting gene) of all three strains and an inhibition of $\mathrm{AFB}_{1}$ production by $A$. flavus EGP9 and $\mathrm{AFG}_{1}$ production by $A$. parasiticus NRRL 13005 . However, there was no significant decrease in $\mathrm{AFG}_{1}$ by $A$. parasiticus SSWT 2999. This suggests that perhaps uptake of siRNA by A. parasiticus SSWT 2999 protoplasts is not as efficient as in A. flavus and the other strain of $A$. parasiticus. Thus source of the strain may influence the effectiveness of the siRNA and the threshold concentrations required may vary. Another explanation may be that the biosynthesis of aflatoxin is slightly different in A. flavus and A. parasiticus. Wilkinson et al. [33] reported that the regulatory mechanism or mechanisms that control aflatoxin production in A. flavus and A. parasiticus are different in response to tryptophan (Trp), where, in the presence of Trp, three aflatoxin biosynthetic pathway genes (aflE (norA), aflD (nor-1), and aflO (omtB)) showed a decrease in expression and $\mathrm{AFB}_{1}$ and $\mathrm{AFB}_{2}$ production for A. flavus while, for $A$. parasiticus, an increase in expression profile and $\mathrm{AFB}_{1}$ and $\mathrm{AFG}_{1}$ production were observed. 


\section{Conclusions}

The present study suggests that the aflD gene has a role in monitoring the biosynthetic direction of aflatoxin biosynthesis in A. flavus and A. parasiticus. This could thus be a good a target gene for inactivation, to develop efficient means of aflatoxin control by using RNA silencing technology. This can be applied, for example, by using mycoviruses as a candidate to mediate and propagate inactivation of the aflD gene.

\section{Acknowledgments}

Ahmed Abdel-Hadi is very grateful to Egyptian Higher Education Ministry and Al-Azhar University, Assuit branch, for financial support. We are very grateful to D. Bhatnagar and P. Cotty for the supply of strains.

\section{References}

1. Peraica, M.; Radic, B.; Lucic, A.; Pavlovic, M. Toxic effects of mycotoxins in humans. Bull. World Health Organ. 1999, 77, 754-766.

2. Ketting, R.F.; Fischer, S.E.; Bernstein, E.; Sijen, T.; Hannon, G.J.; Plasterk, R.H. Dicer functions in RNA interference and in synthesis of small RNA involved in developmental timing in C. elegans. Genes Dev. 2001, 15, 2654-2659.

3. Bromley, M.; Gordon, C.; Rovira-Graells, N.; Oliver, J. The Aspergillus fumigatus cellobiohydrolase B (cbhB) promoter is tightly regulated and can be exploited for controlled protein expression and RNAi. FEMS Microbiol. Lett. 2006, 264, 246-254.

4. de Jong, J.F.; Deelstra, H.J.; Wosten, H.A.; Lugones, L.G. RNA mediated gene silencing in monokaryons and dikaryons of Schizophyllum commune. Appl. Environ. Microbiol. 2006, 72, 1267-1269.

5. Mouyna, I.; Henry, C.; Doering, T.L.; Latge, J.P. Gene silencing with RNA interference in the human pathogenic fungus Aspergillus fumigatus. FEMS Microbiol. Lett. 2004, 237, 317-324.

6. Nakayashiki, H. RNA silencing in fungi: Mechanisms and applications. FEBS Lett. 2005, 579, 5950-5957.

7. Liu, H.; Cottrell, T.R.; Pierini, L.M.; Goldman, W.E.; Doering, T.L. RNA interference in the pathogenic fungus Cryptococcus neoformans. Genetics 2002, 160, 463-470.

8. Khatri, M.; Rajam, M.V. Targeting polyamines of Aspergillus nidulans by siRNA specific to fungal ornithine decarboxylase gene. Med. Mycol. 2007, 45, 211-220.

9. Whisson, S.C.; Avrova, A.O.; West, P.V.; Jones, J.T. A method for double-stranded RNA mediated transient gene silencing in Phytophthora infestans. Mol. Plant Pathol. 2005, 6, 153-163.

10. Trail, F.; Chang, P.K.; Cary, J.; Linz, J.E. Structural and functional analysis of the nor-1 gene involved in the biosynthesis of aflatoxins by Aspergillus parasiticus. Appl. Environ. Microbiol. 1994, 60, 4078-4085.

11. Zhou, R.; Linz, J.E. Enzymatic function of the Nor-1 protein in aflatoxin biosynthesis in Aspergillus parasiticus. Appl. Environ. Microbiol. 1999, 65, 5639-5641. 
12. Cary, J.W.; Montalbano, B.G.; Ehrlich, K.C. Promoter elements involved in the expression of the Aspergillus parasiticus aflatoxin biosynthesis pathway gene avnA. Biochim. Biophys. Acta 2000, 1491, 7-12.

13. Schmidt-Heydt, M.; Abdel-Hadi, A.; Magan, N.; Geisen, R. Complex regulation of the aflatoxin biosynthesis gene cluster of Aspergillus flavus in relation to various combinations of water activity and temperature. Int. J. Food Microbiol. 2009, 135, 231-237.

14. Abdel-Hadi, A.; Carter, D.; Magan, N. Temporal monitoring of the nor-1 (aflD) gene of Aspergillus flavus in relation to aflatoxin $\mathrm{B}_{1}$ production during storage of peanuts under different environmental conditions. J. Appl. Microbiol. 2010, 109, 1914-1922.

15. Abdel-Hadi, A.; Carter, D.; Magan, N. Discrimination between aflatoxigenic and non-aflatoxigenic strains of Aspergillus section flavi group contaminating Egyptian peanuts using molecular and analytical techniques. World Mycotoxin J. 2011, 4, 69-77.

16. Cary, J.W.; Ehrlich, K.C.; Kate, S.P.; Calvo, A.M.; Bhatnagar, D.; Cleveleand, D.E. Regulatory elements in aflatoxin biosynthesis. Mycotoxin Res. 2006, 22, 105-109.

17. Natural Toxins. In Official Methods of Analysis of AOAC International, 17th ed.; Association of Official Analytical Chemists: Washington, DC, USA, 2000; Chapter 49.

18. Mayer, Z.; Bagnara, A.; Färber, P.; Geisen, R. Quantification of the copy number of nor-1, a gene of the aflatoxin biosynthetic pathway by real-time PCR, and its correlation to the cfu of Aspergillus flavus in foods. Int. J. Food Microbiol. 2003, 82, 143-151.

19. Geisen, R. Multiplex polymerase chain reaction for the detection of potential aflatoxin and sterigmatocystin producing fungi. Syst. Appl. Microbiol. 1996, 19, 388-392.

20. Bustin, S.A. Absolute quantification of mRNA using real-time reverse transcription polymerase chain reaction assays. J. Mol. Endocrinol. 2000, 25, 169-193.

21. Fire, A.; Xu, S.; Montgomery, M.K. Potent and specific genetic interference by double-stranded RNA in C. elegans. Nature 1998, 391, 806-811.

22. Zamore, P.D.; Tuschl, T.; Sharp, P.A.; Bartel, D.P. RNAi: Double-stranded RNA directs the ATP-dependent cleavage of mRNA at 21 to 23 nucleotide intervals. Cell 2000, 101, 25-33.

23. Nakayashiki, H.; Nguyen, Q.B. RNA interference: Roles in fungal biology. Curr. Opin. Microbiol. 2008, 11, 494-502.

24. Skory, C.D.; Chang, P.K.; Linz, J.E. Regulated expression of the nor-1 and ver-1 genes associated with aflatoxin biosynthesis. Appl. Environ. Microbiol. 1993, 59, 1642-1646.

25. Yu, J.; Chang, P.K.; Ehrlich, K.C.; Cary, J.W.; Bhatnagar, D.; Cleveland, R.E.; Payne, G.A.; Linz, J.E.; Woloshuk, C.P.; Bennett, J.W. Clustered pathway genes in aflatoxin biosynthesis. Appl. Environ. Microbiol. 2004, 70, 1253-1262.

26. Bennett, J.W. Loss of norsolorinic acid and aflatoxin production by a mutant of Aspergillus parasiticus. J. Gen. Microbiol. 1981, 124, 429-432.

27. McDonald, T.; Brown, D.; Keller, N.P.; Hammond, T.M. RNA silencing of mycotoxin production in Aspergillus and Fusarium species. Mol. Plant-Microbe Interact. 2005, 18, 539-545.

28. Hammond, T.M.; Keller, N.P. RNA silencing in Aspergillus nidulans is independent of RNA-dependent RNA polymerases. Genetics 2005, 169, 607-617.

29. Butchko, R.A.E.; Adams, T.H.; Keller, N.P. Aspergillus nidulans mutants defective in stc gene cluster regulation. Genetics 1999, 153, 715-720. 
30. Trail, F.; Mahanti, N.; Rarick, M.; Mehigh, R.; Liang, S.H.; Zhou, R.; Linz, J.E. Physical and transcriptional map of an aflatoxin gene cluster in Aspergillus parasiticus and functional disruption of a gene involved early in the aflatoxin pathway. Appl. Environ. Microbiol. 1995, 61, 2665-2673.

31. Yabe, K.; Nakamura, Y.; Nakajima, H.; Ando, Y.; Hamasaki, T. Enzymatic conversion of norsolorinic acid to averufin in aflatoxin biosynthesis. Appl. Environ. Microbiol. 1991, 57, $1340-1345$.

32. Jackson, A.L.; Bartz, S.R.; Schelter, J.; Kobayashi, S.V.; Burchard, J.; Mao, M.; Li, B.; Cavet, G.; Linsley, P.S. Expression profiling reveals off-target gene regulation by RNAi. Nat. Biotechnol. 2003, 21, 635-637.

33. Wilkinson, J.R.; Yu, J.; Bland, J.M.; Nierman, W.C.; Bhatnagar, D.; Cleveland, T.E. Amino acid supplementation reveals differential regulation of aflatoxin biosynthesis in Aspergillus flavus NRRL 3357 and Aspergillus parasiticus SRRC 143. Appl. Microbiol. Biotechnol. 2007, 74, $1308-1319$.

(C) 2011 by the authors; licensee MDPI, Basel, Switzerland. This article is an open access article distributed under the terms and conditions of the Creative Commons Attribution license (http://creativecommons.org/licenses/by/3.0/). 